\title{
Methods Dealing with Complexity in Selecting Joint Venture Contractors for Large-Scale Infrastructure Projects
}

\author{
Ru Liang $\mathbb{D}^{1}{ }^{1}$ Zhaohan Sheng, ${ }^{1}$ and Xiangyu Wang ${ }^{2,3}$ \\ ${ }^{1}$ School of Management and Engineering, Nanjing University, Nanjing 210093, China \\ ${ }^{2}$ School of Built Environment, Curtin University, Perth, WA 6102, Australia \\ ${ }^{3}$ Department of Housing and Interior Design, Kyung Hee University, Seoul 130701, Republic of Korea \\ Correspondence should be addressed to Ru Liang; rliang124@163.com
}

Received 17 July 2017; Accepted 19 November 2017; Published 3 January 2018

Academic Editor: Daniela Paolotti

Copyright (c) $2018 \mathrm{Ru}$ Liang et al. This is an open access article distributed under the Creative Commons Attribution License, which permits unrestricted use, distribution, and reproduction in any medium, provided the original work is properly cited.

\begin{abstract}
The magnitude of business dynamics has increased rapidly due to increased complexity, uncertainty, and risk of large-scale infrastructure projects. This fact made it increasingly tough to "go alone" into a contractor. As a consequence, joint venture contractors with diverse strengths and weaknesses cooperatively bid for bidding. Understanding project complexity and making decision on the optimal joint venture contractor is challenging. This paper is to study how to select joint venture contractors for undertaking large-scale infrastructure projects based on a multiattribute mathematical model. Two different methods are developed to solve the problem. One is based on ideal points and the other one is based on balanced ideal advantages. Both of the two methods consider individual difference in expert judgment and contractor attributes. A case study of Hong Kong-Zhuhai-Macao-Bridge (HZMB) project in China is used to demonstrate how to apply these two methods and their advantages.
\end{abstract}

\section{Introduction}

Rapid urbanization in recent years has increased the number of construction projects with large amounts of dollars invested in large-scale infrastructure projects [1]. These projects are usually highly complicated [2] and beset with issues such as low performance, schedule delays, and cost overruns $[3,4]$ because of lacking relevant knowledge on the part of project managers, especially an appropriate joint venture constructor [5]. These challenges present a paradox: a few of these demands directly contribute to the physical construction of the project; however, a failure to properly manage them can lead to problems for the entire project and construction team [6]. Therefore, understanding project complexity and selecting an appropriate joint venture contractor in the process of construction management are extremely critical and very difficult for large-scale infrastructure projects because of its complexity and dynamic environment [7].

Many scholars have carried out a great number of research studies to identify the selection attributes and categorize these attributes of contractors [8-12]. Hatush and Skitmore [8] proposed a set of attributes classified into five categories to assess contractors, including financial soundness, technical ability, management capability, health and safety, and reputation. However, this work is criticized, for example, for lacking consistency. The study by Lam et al. [9] presents an artificial neural network as a decision support tool for prequalifying contractors through examination of the multiple contractor competitive attributes like technical strength, financial status, and so on. These studies have led to a recent study by Shen et al. [10] that summarizes competitive attributes of contractors as social influence, technical ability, financing ability and accounting status, marketing ability, management skills, and organizational structure and operations. Nevertheless, it is not satisfactory for decision makers (DMs) anymore to evaluate the contractor's performance just by using competitive attributes [11]. Indeed, joint venter contractor selection is a critical decision that influences the project success and therefore cooperation attributes must be taken into consideration [12]. As a result, many different attempts have been made for contractor selection based on 
competitive attributes and cooperation attributes at the same time [13].

There are a number of existing tools and methods formulated to evaluate and select joint venture contractors, including the multiattribute analysis such as Zavadskas et al. [14] and multiattribute utility theory (especially among "earlier" studies in the field), along with several interpretations of artificial neural networks (ANN) [15], multivariate discriminant analysis [16], fuzzy theory [17], and analytical hierarchy process (AHP) [18]. Researchers Zavadskas et al. [14] used the multiattribute method to assess and select contractors by specifically developing a model that takes into account all attributes affecting construction efficiency. The ANP-Monte Carlo simulated model proposed by El-Abbasy et al. [19] is a novel approach where multiattribute is considered to select the best contractor for highway projects. Furthermore, analysis of the methodological approaches was based on the chosen categories of statistical/deterministic modelling [20], literature/documentary analysis [21], surveys [22], and other nondeterministic forms [23-28].

Despite the fact that the literature is rich with approaches and models for contractor selection, the two important issues of interdependency and uncertainty were not addressed concurrently. The decision-making process in the bidding stage is influenced by cooperation attributes and competitive attributes that should characterize any competitive joint venter contractor [8-10, 29]. Furthermore, those attributes are not isolated from the bidding system structure and its turbulent environment [11]. The second issue concerns the uncertainty inborn as for the subjectivity of attribute weighting. Different respondents gave different answers. Overall, the issue of integrating a system of interdependency and simulation has not yet been addressed.

To address this drawback, this research aims at developing: (1) an analyzed model of selecting joint venter contractor in large-scale infrastructure projects to solve interdependency of one joint venter contractor through considering competitive attributes besides cooperation attributes. A good joint venter contractor should be with good performance in competition and cooperation at the same time, which needs decision methods that can reflect the balance [11-13]. (2) Two proposed methods evaluate importance of alternative joint venter contractors for solving the uncertainty of attribute weighting by utilizing linguistic variables. Selecting joint venter contractor involves gathering of the candidates' objective statistics and the experts' subjective evaluation information [30-32]. This research considers that experts have different weights to evaluate attribute values and their weights by utilizing linguistic variables, which is lean close to construction practice.

The rest of this paper is organized as follows. In Section 2, the preliminaries on triangular fuzzy numbers, linguistic variables, and TOPSIS method are briefly introduced. In Section 3, research problem and analyzed model are described. Section 4 develops two proposed methods, followed by a case study of Hong Kong-Zhuhai-Macao-Bridge (HZMB) project in China to demonstrate selection of bridge route and project complexity in Section 5. The final section presents the conclusions for the proposed methods.

\section{Preliminaries}

In this section, some preliminaries are briefly introduced, including triangular fuzzy numbers, linguistic variables, and TOPSIS method.

2.1. Triangular Fuzzy Numbers. A triangular fuzzy number $\widehat{A}$ can be defined by a triplet $\left(d^{L}, d^{M}, d^{R}\right)$. Its membership function $\mu_{\widehat{A}}(x)$ is defined as [33]

$$
\mu_{\widehat{A}}(x)= \begin{cases}0, & x<d^{L} \\ \frac{\left(x-d^{L}\right)}{\left(d^{M}-d^{L}\right)}, & d^{L} \leq x \leq d^{M} \\ \frac{\left(d^{R}-x\right)}{\left(d^{R}-d^{M}\right)}, & d^{M} \leq x \leq d^{R} \\ 0, & x>d^{R},\end{cases}
$$

where $d^{L}, d^{M}$, and $d^{R}$ are real numbers and $d^{L} \leq d^{M} \leq d^{R}$. If $x=d^{M}$, then the grade $\mu_{\widehat{A}}(x)$ is maximal (i.e., $\mu_{\widehat{A}}(x)=1$ ), and $d^{M}$ is the most probable value of the evaluation data. Constants $d^{L}$ and $d^{R}$ are the lower and upper bounds of the available range for the evaluation data, respectively.

The Euclidean distance of two triangular fuzzy numbers $\widehat{A}_{1}=\left(d_{1}^{L}, d_{1}^{M}, d_{1}^{R}\right)$ and $\widehat{A}_{2}=\left(d_{2}^{L}, d_{2}^{M}, d_{2}^{R}\right)$ is defined as [33]

$$
\begin{aligned}
& \left(\widehat{A}_{1}, \widehat{A}_{2}\right) \\
& =\sqrt{\frac{1}{3}\left[\left(d_{1}^{L}-d_{2}^{L}\right)^{2}\right]+\left[\left(d_{1}^{M}-d_{2}^{M}\right)^{2}\right]+\left[\left(d_{1}^{R}-d_{2}^{R}\right)^{2}\right] .}
\end{aligned}
$$

Readers who are interested in fuzzy numbers can refer to papers by Kaufmann and Gupta [34].

2.2. Linguistic Variables. A linguistic variable is a variable whose values are words or sentences of a natural or artificial language that are expressed in linguistic terms which are then represented by the triangular fuzzy number [35]. Usually, conversion scales are used to transform linguistic terms into fuzzy numbers [36]. In this research work, we use 0-1 scale and $0-10$ scale to rate the attributes and alternatives, respectively.

2.3. TOPSIS Method. The TOPSIS (technique for order preference by similarity to ideal solution) is one of the most used multiattribute methods for solving multiattribute decisionmaking problems as it is easy to assimilate and apply. Indeed, the principle is based on finding the closest alternative to Ideal Reference Point (IRP) (i.e., the solution that maximizes the advantages attributes and which minimizes the costs attributes) noted IRP and the farthest alternative to the AntiIdeal Reference Point (ARP) (i.e., the solution that maximizes the costs attributes and which minimizes advantages attribute). Four steps are needed as follows [37]. 
Step 1. Construct weighted collective preferences matrix.

The weighted fuzzy collective preferences matrix through massing the index weight vector and decision-making information matrix is constructed as

$$
P^{\prime \prime}=\left[\begin{array}{cccc}
p_{1}^{\prime \prime(1)} & p_{1}^{\prime \prime(2)} & \cdots & p_{1}^{\prime \prime(l)} \\
p_{2}^{\prime \prime(1)} & p_{2}^{\prime \prime(2)} & \cdots & p_{2}^{\prime \prime(l)} \\
\vdots & \vdots & \ddots & \vdots \\
p_{m}^{\prime \prime(1)} & p_{m}^{\prime \prime(2)} & \cdots & p_{m}^{\prime \prime(l)}
\end{array}\right],
$$

where $p_{i}^{\prime \prime(k)}$ can be obtained by the following formula:

$$
p_{i}^{\prime \prime(k)}=p_{i}^{\prime(k)} \cdot v_{k}^{(l)}, \quad i=1,2, \ldots, m ; k=1,2, \ldots, l .
$$

Step 2. Determine the ideal and anti-ideal alternatives.

The positive ideal solution (PIS) and negative ideal solution (NIS) are defined as

$$
\begin{aligned}
\mathrm{PIS} & =\left(\delta_{1}^{+}, \delta_{2}^{+}, \ldots, \delta_{l}^{+}\right), \\
\mathrm{NIS} & =\left(\delta_{1}^{-}, \delta_{2}^{-}, \ldots, \delta_{l}^{-}\right),
\end{aligned}
$$

where $\delta_{k}^{+}=1, \delta_{k}^{-}=-1, k=1,2, \ldots, l$.

Step 3. Calculate the distances of each initial alternative to the PIS and NIS.

The distances of each candidate team from the PIS and NIS are calculated as

$$
\begin{aligned}
& d_{i}^{+}=\sum_{k=1}^{l} d\left(p_{i}^{\prime \prime(k)}, \delta_{k}^{+}\right), \quad i=1,2, \ldots, m, \\
& d_{i}^{-}=\sum_{k=1}^{l} d\left(p_{i}^{\prime \prime(k)}, \delta_{k}^{-}\right), \quad i=1,2, \ldots, m,
\end{aligned}
$$

where $d\left(p_{i}^{\prime \prime(k)}, \delta_{k}^{+}\right)$and $d\left(p_{i}^{\prime \prime(k)}, \delta_{k}^{-}\right)$are the distances between two clear numbers, which are calculated as

$$
\begin{aligned}
& d\left(p_{i}^{\prime \prime(k)}, \delta_{k}^{+}\right)=\left|p_{i}^{\prime \prime(k)}, \delta_{k}^{-}\right|, \quad i=1,2, \ldots, m, \\
& d\left(p_{i}^{\prime \prime(k)}, \delta_{k}^{-}\right)=\left|p_{i}^{\prime \prime(k)}, \delta_{k}^{-}\right|, \quad i=1,2, \ldots, m .
\end{aligned}
$$

Step 4. Obtain the closeness coefficient and rank the order of alternatives.

The closeness coefficients $\mathrm{CC}_{i}$ of each alternative are calculated as

$$
\mathrm{CC}_{i}=\frac{d_{i}^{-}}{d_{i}^{+}+d_{i}^{-}}, \quad i=1,2, \ldots, m .
$$

\section{Analysis Model and Problem Description}

In this section, a matrix analysis model based on competitive attributes and cooperation attributes is presented. Then, the bidimensional and balanced performance problem for joint venter contractor selection of large-scale infrastructure projects based on the matrix analysis model is formulated.
3.1. Construct an Analyzed Model. Based on the above introduction, joint venter contractor selection needs to consider competitive attributes and cooperation attributes at the same time. Moreover, candidate joint venter contractors are irreplaceable on evaluation results on these two aspects; that is, the joint venter contractor who has good competitive and poor cooperation or the joint venter contractor who has good cooperation and poor competitiveness is not a desired option. Only the joint venter contractor who has good performance of these two aspects is the ideal choice. Thus, in order to avoid information flood caused by gathering multiattribute information directly, this paper constructs a matrix analysis model of joint venter contractor selection. The $X$-axis and $Y$-axis represent performances of cooperation and competitiveness, respectively. Curves of the model are performance curves. The points on the diagonal manifest the best balance of the two kinds of attributes; while the points that approached the axes manifest the worst balance of the two kinds of attributes.

In order to further clarify use and measure of the matrix analysis model, on the basis of studies by numerous scholars proposed in Introduction, this paper constructs cooperation attributes and competitive attributes of joint venter contractors, respectively. Competitive attributes consider evaluating attributes: strength and credibility, technical strength, resource strength, and quotation. For cooperation, peer reviewers are different to give their subjective judgments as a result of limitations to understand actual cooperation situation among the candidate joint venter contractors. Therefore, evaluating attributes, compatible culture, contract, communication, collaboration, cooperation ability, and cooperation satisfaction, are adopted in this paper. A detailed description is as follows:

(i) Strength and credibility: comprehensive evaluation on joint venture contractors of fixed assets, liquidity, credit rating, the construction machinery and equipment, and so on [38].

(ii) Technical strength: new technology or experience in a certain field $[39,40]$.

(iii) Resource strength: all kinds of production factors, which can be owned, controlled, or used to achieve goals [41].

(iv) Quotation: project value of reviewed in [42].

(v) Compatible culture: consistent cognitive expectations, mental models, ethics, and values between two contractors $[43,44]$.

(vi) Contract: an agreement of mutual rights and obligations among all joint venter contractors [44].

(vii) Communication: the contents of the cooperation and coordination [45].

(viii) Collaboration: ability to achieve maximum efficiency by developing team spirit and complementary mutual [46].

(ix) Cooperation ability: ability of coordination and cooperation acquired in engineering [42].

(x) Cooperation satisfaction: satisfied cooperation and willingness to cooperate continuously [42]. 
To be more efficiently assessed, the attributes above defined must be decomposed into subattribute as shown in Figure 1. Without wishing to be exhaustive because subattribute can be different depending on the nature of large-scale infrastructure projects, basic decomposition of competitive and collaboration subattribute is shown in Tables 1 and 2, respectively.

3.2. Problem Description. Based on the analyzed model and the attribute system constructed in Section 3.1, this paper aims to develop decision methods to support joint venter contractor selection of bidding in construction projects.

Suppose a set of feasible alternative joint venter contractors is $P=\left\{P_{h} \mid h=1,2, \ldots, z\right\}$, where $h$ denotes ranking of the alternatives and $z$ is total number of the alternatives. Let $E=\left\{E_{l} \mid l=1,2, \ldots, q ; q \geq 2\right\}$ be a limited amount set of experts, where $q$ is the total number of experts; $E_{l}$ is the $l$ th expert invited to participate in joint venter contractor selection. Suppose the weight vectors of competitive attributes and cooperation attributes provided by the expert $E_{l}$ are $\widetilde{W} I_{l}=\left\{\widetilde{w} i_{1 l}, \widetilde{w} i_{2 l}, \ldots, \widetilde{w} i_{m l}\right\}$ and $\widetilde{W} C_{l}=$ $\left\{\widetilde{w} c_{1 l}, \widetilde{w} c_{2 l}, \ldots, \widetilde{w} c_{n l}\right\}$, respectively. Here, $\widetilde{w} i_{j l}$ is the attribute weights of competitive attribute $I_{i} ; \widetilde{w} c_{j l}$ is the attribute weight of cooperation attribute $C_{j} . \widetilde{d}_{h i k} \in U$ is linguistic assessment information on competitive attribute $I_{i}$ of the alternative joint venter contractor $P_{h}$ given by expert $E_{l}$, where $k$ is the $j$ th expert. The matrix form of competitive assessment information given by experts can be expressed as

$$
D_{k}=\left[\begin{array}{cccc}
d_{11 k} & d_{12 k} & \cdots & d_{1 m k} \\
d_{21 k} & d_{22 k} & \cdots & d_{2 m k} \\
\vdots & \vdots & - & \vdots \\
d_{q 1 k} & d_{q 2 k} & \cdots & d_{q m k}
\end{array}\right], \quad k=1,2, \ldots, l .
$$

The matrix form of cooperation assessment information given by experts can be expressed as

$$
Y_{k}=\left[\begin{array}{cccc}
- & y_{12 k} & \cdots & y_{1 m k} \\
y_{21 k} & - & \cdots & y_{2 m k} \\
\vdots & \vdots & - & \vdots \\
y_{q 1 k} & y_{q 2 k} & \cdots & -
\end{array}\right], \quad k=1,2, \ldots, l .
$$

To facilitate our analysis, we integrate the above two matrices into the following matrix form:

$$
C_{k}=\left[\begin{array}{cccc}
c_{11 k} & c_{12 k} & \cdots & c_{1 q k} \\
c_{21 k} & c_{22 k} & \cdots & c_{2 q k} \\
\vdots & \vdots & - & \vdots \\
c_{q 1 k} & c_{q 2 k} & \cdots & c_{q q k}
\end{array}\right], \quad k=1,2, \ldots, l .
$$

Suppose experts have different importance (i.e., different judgment ability levels of the experts) in this paper. Denote $\mu=\left\{\mu_{t} \mid t=l, \ldots, q\right\}$ as the judgment level of the expert $E_{l}$. Let a set of competitive attributes and cooperation attributes be $I=\left\{I_{i} \mid i=1,2, \ldots, m\right\}$ and $C=\left\{C_{j} \mid\right.$ $j=1,2, \ldots, n\}$, respectively. Here, $I_{i}$ is the $i$ th competitive attribute to evaluate performance of each joint venter contractor; $C_{j}$ is the $j$ th cooperation attribute to evaluate performance of each joint venter contractor.

Here experts are invited to participate in joint venter contractor selection, who give the matrix forms of competitive and cooperation evaluation information. Traditional evaluation approaches assume that the experts have the same weights. However, this is not consistent with engineering practice. From a practice perspective, it is generally considered that the judgment abilities of individuals tend to become more sophisticated and stable with the accrual of educational background and working experience. According to Zhang et al. [30], the judgment ability $\mu$ is divided into four levels, represented by "I-IV" as shown in Table 3 . The level I with a score $\mu=1.00$ represents the highest reliability of the expert judgment ability. The level IV with a score $\mu=0.7$ represents the lowest reliability of the expert judgment ability.

The decision matrix of competitive attribute data and the decision matrix of cooperation attribute data provided by the expert $E_{l}$ can be combined. The problem addressed in this paper is how to rank alternative joint venture contractors or to select desired alternative joint venture contractor(s) from the finite set $P$ according to the weight vectors $\widetilde{W} I_{l}=$ $\left\{\widetilde{w} i_{1 l}, \widetilde{w} i_{2 l}, \ldots, \widetilde{w} i_{m l}\right\}$ and $\widetilde{W} C_{l}=\left\{\widetilde{w} c_{l l}, \widetilde{w} c_{2 l}, \ldots, \widetilde{w} c_{n l}\right\}$.

\section{Joint Venture Contractor Selection Methods}

Based on gathering performance of competitive attributes and cooperation attributes, comprehensive evaluation values of joint venture contractors can be obtained further. On the basis of above analysis, the selected joint venture contractor needs to have good performance both on competitive attributes and cooperation attributes. Thus, the proposed bidimension index information gathering methods need to manifest the best balance of the two kinds of attributes.

4.1. The First Proposed Method. This section develops a new method of massing di-dimensional attribute information based on TOPSIS. According to comprehensive values of competitive and cooperation attributes, a joint venture contractor can be represented as a point in Cartesian coordinate system. The candidate which is close to the positive ideal point and is far away from the negative ideal point has optimal balance performance. Thus, it needs closeness coefficients and deviation coefficients to be far away from the straight line to measure performances of joint venture contractors. The points in symmetry area above the axis have the same principle as for symmetry. The specific process of the method is as follows.

4.1.1. Gathering Information and Ranking Joint Venture Contractors Based on Ideal Points. A joint venture contractor can be written as the point $A\left(x_{i}, y_{i}\right)$ in the Cartesian coordinate system. Here, $x_{i}$ is competitive attributes information; $y_{i}$ is 


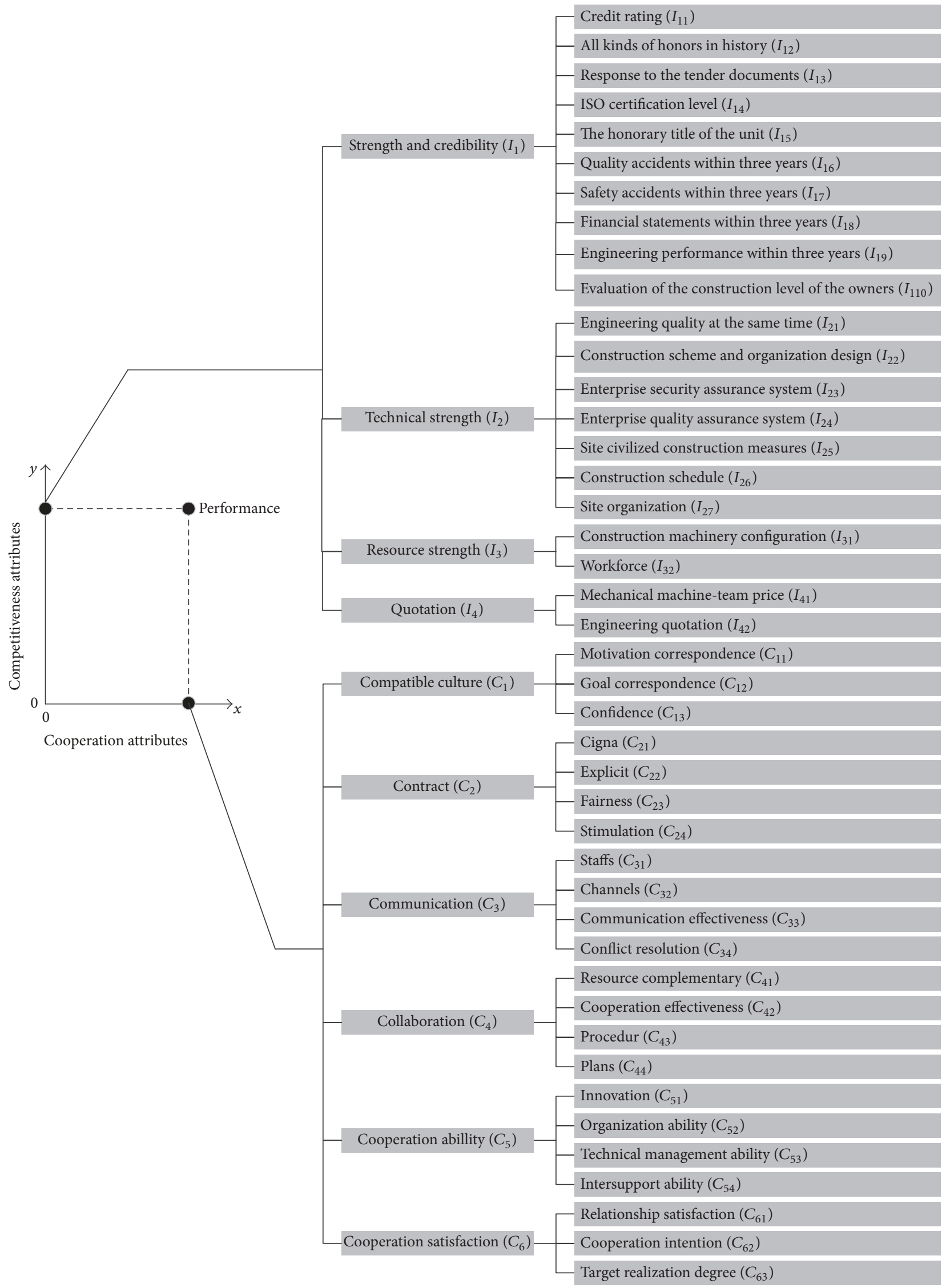

FIGURE 1: The evaluating attribute system of performance for joint venter contractors. 
TABle 1: A basic decomposition of competitive subattribute (Source from: [8-12, 23]).

\begin{tabular}{|c|c|}
\hline Subattributes & Description \\
\hline$I_{11}$ & Financial situation, management skills and ability \\
\hline$I_{12}$ & Praise and awards acquired from the society and the public \\
\hline$I_{13}$ & Response on the substantial requirements in the tender documents \\
\hline$I_{14}$ & Ability to provide products which meet the requirements of the owners and the applicable regulatory requirements \\
\hline$I_{15}$ & Honor titles awarded by external agencies \\
\hline$I_{16}$ & Project quality does not conform to the regulations, specifications or quality standards stipulated in the contract \\
\hline$I_{17}$ & Harm the personal safety and health, damage the equipment, or cause economic losses \\
\hline$I_{18}$ & Accounting statements reflected the financial and management status of accounting subjects \\
\hline$I_{19}$ & Achievements on schedule, such as the quality rating, salary, benefits, etc. \\
\hline$I_{110}$ & Evaluation on expected building products from the owners to the enterprises \\
\hline$I_{21}$ & Number of completed project entities during the same period \\
\hline$I_{22}$ & Organization of the project construction \\
\hline$I_{23}$ & Organizational structure, procedures, processes and resources required for implementation of safety management \\
\hline$I_{24}$ & $\begin{array}{l}\text { All the planned and systematic activities for making sure that a product or a service can satisfy the given quality } \\
\text { requirements }\end{array}$ \\
\hline$I_{25}$ & Civilized construction in construction areas \\
\hline$I_{26}$ & Construction sequence, plans of the construction and completion date for the proposed projects \\
\hline$I_{27}$ & Design and establish of organization system, organization operation and adjustment \\
\hline$I_{31}$ & Machines and equipment used in the construction process \\
\hline$I_{32}$ & Level of the enterprises staff \\
\hline$I_{41}$ & All of the costs incurred in a working class of a construction machinery under normal operation conditions \\
\hline$I_{42}$ & Project costs proposed by the bidders considering the profits, the corresponding calculation offer after risk cost, etc. \\
\hline
\end{tabular}

TABle 2: A basic decomposition of collaboration subattribute (Source from: [10-12, 23]).

\begin{tabular}{|c|c|}
\hline Subattributes & Description \\
\hline$C_{11}$ & Perceived hidden motives between with two enterprises \\
\hline$C_{12}$ & Consistency to improve the desired and increasing incomes \\
\hline$C_{13}$ & Believe or expectations of the importance for cooperation, and practice of trust \\
\hline$C_{21}$ & Willing to commit to duties and cooperation, and commitment \\
\hline$C_{22}$ & The explicit contracts about the fairness and risks \\
\hline$C_{23}$ & Satisfied with the content and the contract price \\
\hline$C_{24}$ & The incentive and constraint mechanism of the contract \\
\hline$C_{31}$ & Harmonious relationships among site management persons \\
\hline$C_{32}$ & Advanced means of communication based on IT technology platform for the communication and coordination \\
\hline$C_{33}$ & Reasonable and operation of joint decision-making mechanism \\
\hline$C_{34}$ & Reasonable conflict resolution mechanism \\
\hline$C_{41}$ & Complementary technology resources for seizing the opportunity \\
\hline$C_{42}$ & Construction activities fully comply with the construction plans \\
\hline$C_{43}$ & Quality, progress, safety and cost management fully implement the lean construction mode \\
\hline$C_{44}$ & Specification of the plan review, acceptance and check \\
\hline$C_{51}$ & The adoption of new technology and new craft, and using plans of advanced management program \\
\hline$C_{52}$ & Reasonable organization structure and clear division of responsibilities \\
\hline$C_{53}$ & Improved technical capabilities of using the new technologies \\
\hline$C_{54}$ & Strong subjective initiative of the staffs \\
\hline$C_{61}$ & Satisfied cooperation \\
\hline$C_{62}$ & Willingness to cooperate continues continuously \\
\hline$C_{63}$ & Degree to achieve the goal of cooperation \\
\hline
\end{tabular}


TABLE 3: Setting of experts' judgment ability levels (Source from: [26]).

\begin{tabular}{ll}
\hline Levels & Descriptions \\
\hline I & (1) Domain experts with more than 30 years of working experience \\
& (2) Professors within the research field of tunnel infrastructure \\
(1) Domain experts with more than $10-20$ years of working experience & (2) Associate professors within the research field of tunnel infrastructure \\
(1) Domain experts with more than $5-10$ years of working experience & (2) Associate professors within the research field of tunnel infrastructure \\
III & Domain experts with more than $1-5$ years of working experience \\
IV &
\end{tabular}

cooperation attributes information. They can be obtained through the following formulas:

$$
\begin{aligned}
& x_{i}=\sum_{k=1}^{h} p_{i}^{\prime \prime(k)}, \\
& y_{i}=\sum_{k=h+1}^{l} p_{i}^{\prime \prime(k)} .
\end{aligned}
$$

Based on $A\left(x_{i}, y_{i}\right)$ in coordinate system of the joint venture contractor $A_{i}$, define the equilibrium coefficient of the two-dimension index performance that can be defined as

$$
E_{i}=\frac{L_{i}^{-}}{L_{i}^{-}+L_{i}^{+}}, \quad i=1,2, \ldots, m,
$$

where $L_{i}^{+}$are distances from the joint venter contractor $A\left(x_{i}, y_{i}\right)$ to the straight line $x=y ; L_{i}^{-}$are the distance from the joint venture contractor $A\left(x_{i}, y_{i}\right)$ to coordinates $(x=0$ or $y=0)$. They can be calculated through the following formulas:

$$
\begin{aligned}
& L_{i}^{+}=\frac{1}{\sqrt{2}}\left|x_{i}-y_{i}\right|, \\
& L_{i}^{-}= \begin{cases}y_{i}, & x_{i} \geq y_{i} \\
x_{i}, & x_{i}<y_{i} .\end{cases}
\end{aligned}
$$

Based on the closeness coefficient of Formula (9) and the equilibrium coefficient of Formula (15), sorting indexes of the joint venture contractors can be further defined as

$$
R_{i}=C_{i} \cdot E_{i}
$$

Obviously, if the joint venture contractor is closer to the positive ideal point and is away from the negative ideal point, or is close to the axis of symmetry $x=y$ and is away from coordinates $x=0$ and $y=0$ at the same time, its balanced ideal advantages are greater; that is, the candidate is more talented. According to $R_{i}$, DMs can order descending the joint venture contractors and choose the anticipant one.

4.1.2. Summary of the First Proposed. Main steps of the proposed method of gathering information and ranking alternatives based on ideal points shown in Figure 2 are summarized as follows.
Step 1. Obtain original decision matrices of competitive and cooperation attribute data, and attribute weight vector based on competitive and cooperation attribute data $\widehat{W} I_{l}$ and $\widehat{W} C_{l}$ scored by experts. Then, calculate performance of competitive attributes and cooperation attributes, respectively.

Step 2. Construct the integrated decision matrix $\widehat{W}$ through Formula (4).

Step 3. Define the PIS and NIS through Formulas (5) and (6), respectively.

Step 4. Calculate the distances $\left(d_{h}^{+}\right)$and $\left(d_{h}^{-}\right)$of each alternative joint venture contractor from the PIS and NIS through Formulas (7)-(8).

Step 5. Calculate the relative closeness $\mathrm{CC}_{i}$ of each alternative joint venture contractor through Formula (9).

Step 6. Determine overall values of bidimensional attributes $x_{i}$ and $y_{i}$ of each alternative joint venture contractor through Formulas (13) and (14), respectively.

Step 7. Calculate the equilibrium coefficient $E_{i}$ of each alternative joint venture contractor through Formulas (15)-(16).

Step 8. Calculate the ranking indexes $R_{i}$ of all the alternative joint venter contractors through Formula (17).

Step 9. Obtain an ordered ranking of all the alternative joint venture contractors or select the desired one(s).

4.2. The Second Proposed Method. Except for the above proposed method balanced bidimension index performance, another method balanced bidimension index performance is proposed in this section. The specific principles and methods are as follows.

4.2.1. Gathering Information and Ranking Joint Venture Contractors Based on Balanced Ideal Advantages. Projection area $D_{x_{i}}^{-}$from a point $\left(x_{i}, y_{i}\right)$ to coordinate axis $x$ is the area enclosed from ligature of $\left(x_{i}, y_{i}\right)$ to the original point $(0,0)$, the vertical line of $\left(x_{i}, y_{i}\right)$ to the coordinate axis $x$, and the coordinate axis $x$. Similarly, projection area $D_{y_{i}}^{-}$from a point $\left(x_{i}, y_{i}\right)$ to coordinate axis $y$ is the area enclosed from ligature of $\left(x_{i}, y_{i}\right)$ to the original point $(0,0)$, the vertical line of $\left(x_{i}, y_{i}\right)$ 


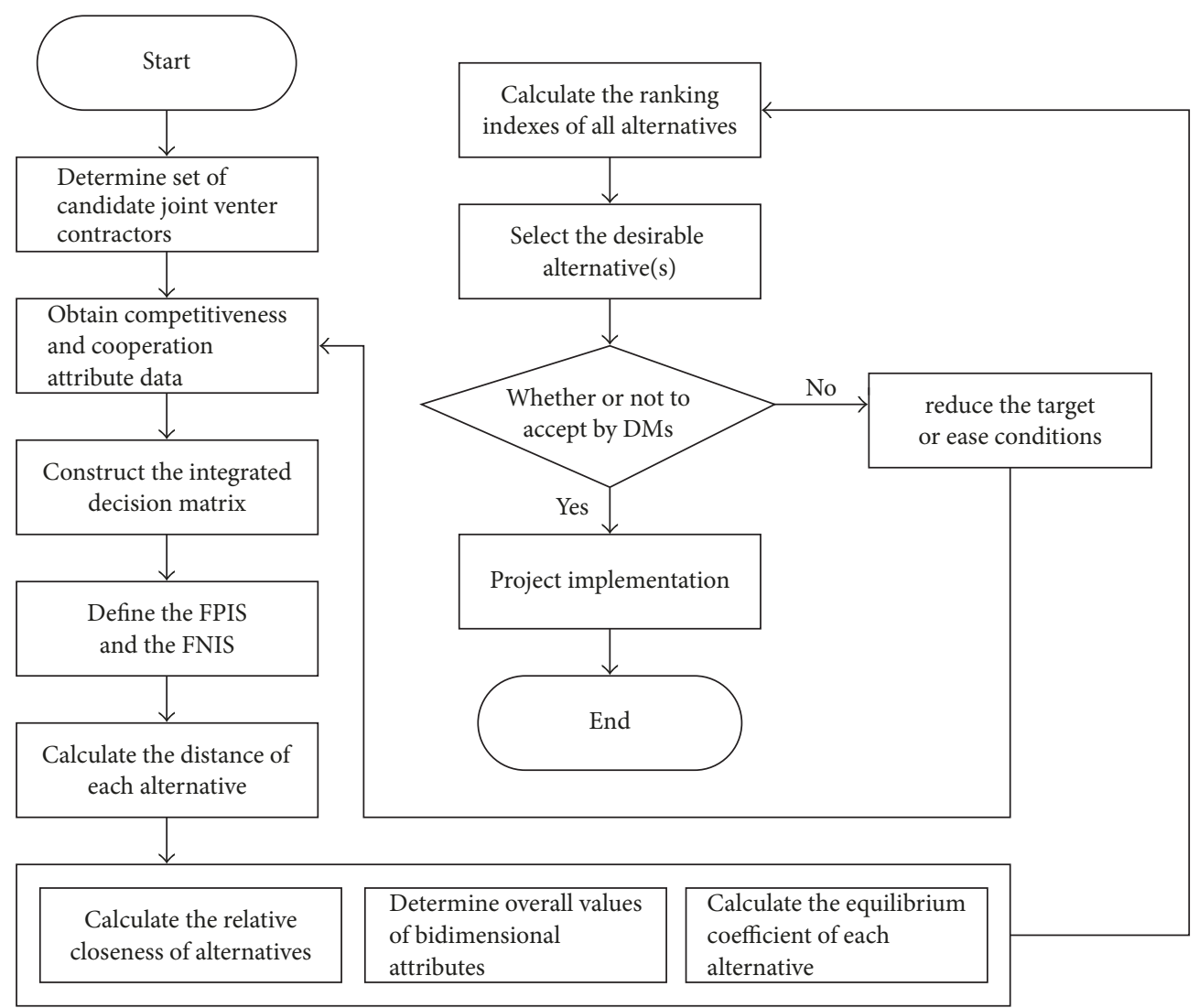

FIGURE 2: The framework of the method based on ideal points.

to the coordinate axis $y$, and the coordinate axis $y$. According to the nature of symmetrical triangles, we have $D_{x_{i}}^{-}=$ $D_{y_{i}}^{-}$, which are unified to be denoted as $D_{i}^{-}$. Therefore, the projection area from a point to coordinate axis is the projection area from the ligature of the point to the original point.

Let $D_{i}^{+}$be the projection areas from the point $\left(x_{i}, y_{i}\right)$ to the line $x=y$. Let $D_{i}^{-}$be the projection areas from the point $\left(x_{i}, y_{i}\right)$ to the coordinate axis. The equilibrium of the point $\left(x_{i}, y_{i}\right)$ distanced with two coordinate axes can be measured as

$$
E_{i}=\frac{D_{i}^{-}}{D_{i}^{-}+D_{i}^{+}} .
$$

We can find that if the point $\left(x_{i}, y_{i}\right)$ is located in the line $x=y$, then the equilibrium of the point $\left(x_{i}, y_{i}\right)$ distanced with two coordinate axis is the best; if the point $\left(x_{i}, y_{i}\right)$ is located in line $x=0$ or $y=0$, then the equilibrium of the point $\left(x_{i}, y_{i}\right)$ distanced with two coordinate axis is the worst. Moreover, the points connected to the original point in a straight line have equivalent equilibrium.

Let $D_{i}^{+}$be the projection areas from the point $\left(x_{i}, y_{i}\right)$ to the line $x=y$. Let $D_{i}^{-}$be the projection areas of the point $\left(x_{i}, y_{i}\right)$ to the coordinate axis. The balanced ideal advantage of the point $\left(x_{i}, y_{i}\right)$ close to the positive ideal point $(1,1)$ and away from the negative ideal point $(0,0)$ can be measured as

$$
C_{i}=\frac{D_{i}^{-}}{D_{i}^{-}+D_{i}^{+}}, \quad 0 \leq C_{i} \leq 1 .
$$

We can find that if the point $\left(x_{i}, y_{i}\right)$ draws near to the negative ideal point $(0,0)$, that is, $C_{i}=0$, the ideal advantage is the smallest; if the point $\left(x_{i}, y_{i}\right)$ draws near to the positive ideal point $(1,1)$, that is, $C_{i}=1$, the ideal advantage is the biggest. Moreover, the points, which connect to the original point in a straight line and draw near to the positive ideal point $(1,1)$ have better ideal advantages. They can be calculated by the following formulas:

$$
\begin{aligned}
& x_{i}=\sum_{k=1}^{h} v_{k}^{(1)} p_{i}^{\prime(k)}, \\
& x_{i}=\sum_{k=h+1}^{l} v_{k}^{(1)} p_{i}^{\prime(k)} .
\end{aligned}
$$

The equilibrium of the point $\left(x_{i}, y_{i}\right)$ distanced two coordinate axis, and the balanced ideal advantages of the point $\left(x_{i}, y_{i}\right)$ draw near to the positive ideal point $(1,1)$ and stayed away from the negative ideal point $(0,0)$ and can be measured as the projection areas $D_{i}^{-}$. Balanced ideal advantage of the point $\left(x_{i}, y_{i}\right)$ is obtained as

$$
R_{i}=\frac{D_{i}^{-}}{D_{i}^{-}+D_{i}^{+}} \times\left(D_{i}^{-}+D_{i}^{+}\right)=D_{i}^{-} .
$$

If the point $\left(x_{i}, y_{i}\right)$ drew near to the positive ideal point $(1,1)$, then the balanced ideal advantages have the fastest growing gradients; if the point $\left(x_{i}, y_{i}\right)$ reached to the point 


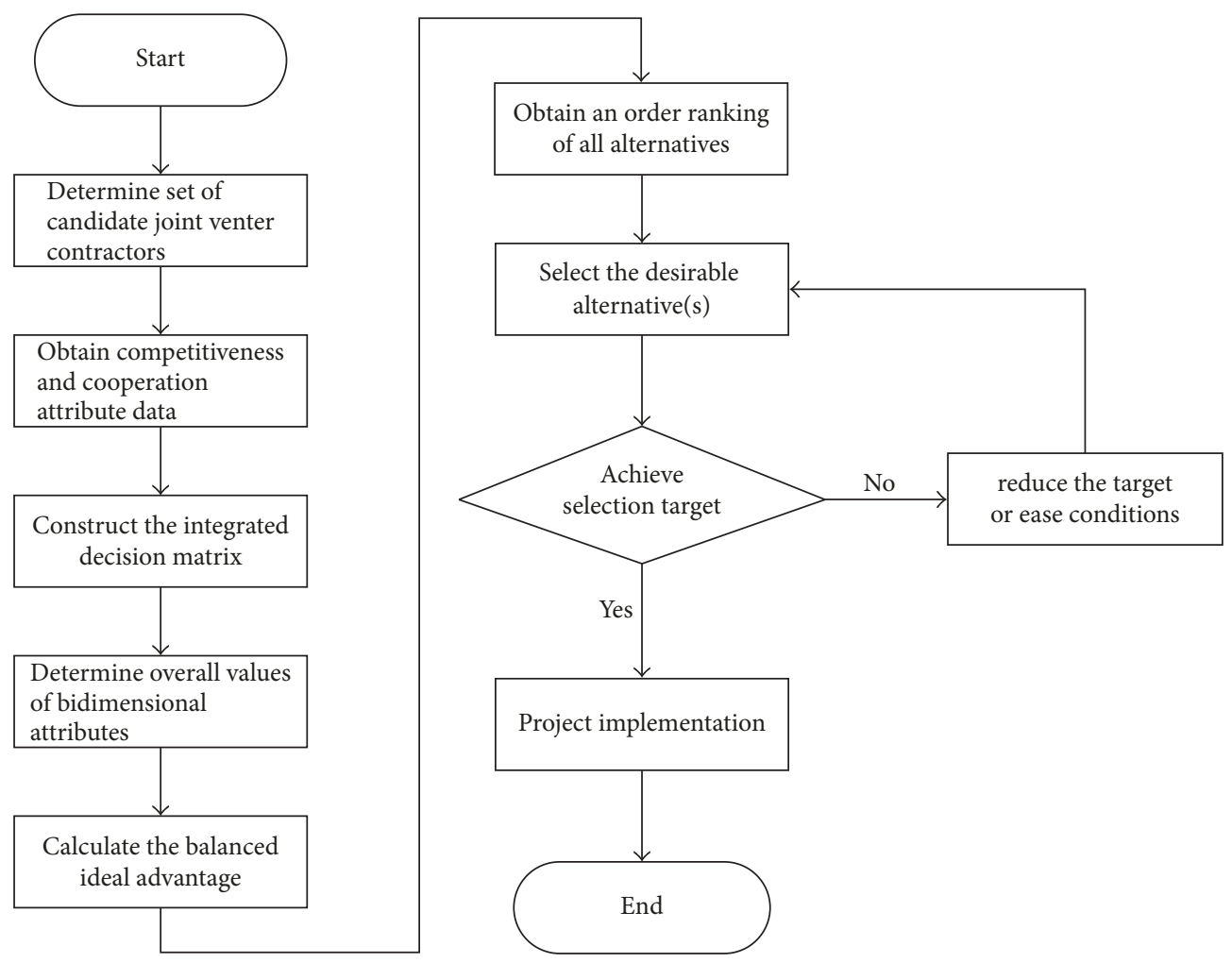

FIgURE 3: The framework of the method based on balanced ideal advantages.

$(1,1)$, its balanced ideal advantage will reach maximum, that is, $R_{i}=1$. Further, the balanced ideal advantage $R_{i}$ of the joint venture contractor $A_{i}$ can be calculated as

$$
R_{i}=\frac{1}{2} x_{i} y_{i}
$$

Obviously, if the joint venture contractor $A_{i}$ has better equilibrium or bigger ideal advantage, then its balanced ideal advantage $R_{i}$ has greater ideal advantage; that is, the candidate is more talented. According to $R_{i}$, DMs can order descendingly the joint venture contractors and choose the anticipant one.

\subsubsection{Steps of the Method Based on Balanced Ideal Advantages.} Main steps of the proposed method of gathering information and ranking the alternatives based on balanced ideal advantages shown in Figure 3 are summarized as follows.

Step 1. Obtain original decision matrices of competitive and cooperation attribute data, and attribute weight vector of competitive and cooperation attribute data $\widehat{W} I_{l}$ and $\widehat{W} C_{l}$ scored by experts. Then, calculate performance of competitive attributes and cooperation attributes, respectively.

Step 2. Construct the integrated decision matrix $\widehat{W}$ through Formulas (20).

Step 3. Determine overall values and bidimensional attributes through Formula (21).
Step 4. Calculate the balanced ideal advantage $R_{i}$ through Formula (22).

Step 5. Obtain an order ranking of all alternative joint venture contractors or select the desired one(s).

\section{Application of Proposed Methods: Case Study}

5.1. Data Sources. According to the overall planning of HZMB, HZMB consists of three major parts: the Offshore Bridge and Tunnel, the Boundary Crossing Facilitates (BCF) at Hong Kong, Zhuhai, and Macao, and the link roads in these three regions. It has been mutually agreed that the offshore bridge and tunnel within mainland Chinese territory (from the Guangdong/Hong Kong border to the BCFs of Zhuhai and Macao) will be built jointly by the three regional governments, and the remaining section in Hong Kong territory will be built by the Hong Kong Government. The BCFs of the three regions and their link roads will be built independently by each jurisdiction. Bad natural environment and difficult construction technology limit the decision of bridge route and landing sites. At the same time, decision of bridge route and landing sites also faces challenges from three aspects: complex decision problems, restriction of decision environment, and insufficient ability of decision-making subjects.

Discussed in this paper is bidding work of artificial islands and tunnels in principal part of the project (hereinafter referred to as the "island and tunnel engineering"). The three 


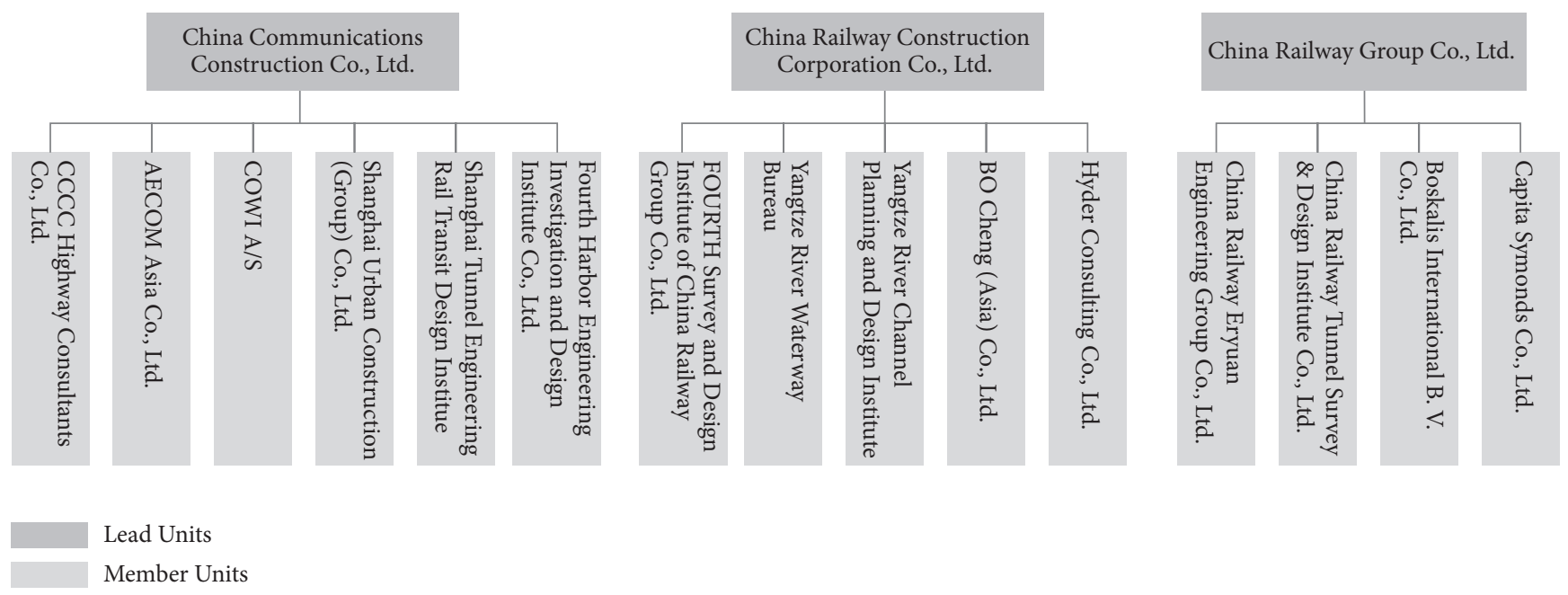

FIGURE 4: Three joint venture contractors of island and tunnel engineering.

bidding teams diagram of island and tunnel engineering is shown in Figure 4.

5.2. Model Results of the $H Z M B$. According to joint venture contractor selection of large-scale infrastructure projects with competitive and cooperation attribute data described in Section 3, we gave the corresponding numerical example that applied the approach put forward in Section 4, and the concrete process is described below.

5.2.1. The First Proposed Method Application. Linguistic assessment information of competitive attributes values, cooperation attribute values, and attribute weights given by four experts (with the assumption of above problem description) through linguistic variables is obtained. The original assessment information is shown in Table 4.

Evaluation information of competitive attributes values and cooperation attributes values given by each expert is calculated and shown in Tables 5 and 6, respectively. Different judgment ability levels of the four experts are considered according to Table 3 . Then the integrated decision matrix is constructed through Formula (3). The calculation results are shown in Table 7 . The weighted integrated decision matrix is constructed through Formula (4) and Tables 3 and 7. The calculation results are shown in Table 8 . The positive ideal point and the negative ideal point are defined as PIS $=(1,1,1,1,1,1,1,1,1,1)$ and NIS $=(-1,-1,-1,-1$, $-1,-1,-1,-1,-1,-1)$ through Formulas (5) and (6), respectively. The distance of each alternative joint venture contractor from the positive ideal point and the negative ideal point are calculated through Formulas (7)-(8). The calculation results are shown in Table 9 . On the basis of the distances from the candidate joint venter contractors to the PIS and NIS, the close coefficients of each alternative can be calculated as $\mathrm{CC}_{1}=0.691, \mathrm{CC}_{2}=0.653$, and $\mathrm{CC}_{3}=0.602$ through Formula (9). According to the bidimensional index information and Formulas (13) and (14), ranking the indices $R_{i}$ of bidimensional attributes can be calculated as $R_{1}=0.662$, $R_{2}=0.451$, and $R_{3}=0.415$. According to $R_{i}$ of bidimensional attributes, the candidate joint venter contractor $R_{1}$ should be chosen.

5.2.2. The Second Proposed Method Application. Based on summarized steps in Section 4.2.2, the two proposed approaches have the same overall values of bidimensional attributes. Thus, the data of Table 7 are used directly here as shown in Table 10. The balanced ideal advantage can be calculated as $R_{1}=0.123, R_{2}=0.111$, and $R_{3}=0.106$.

5.2.3. Discussion. From comparative results of the two proposed methods, we can find that the method based on ideal points (Approach 1) and the method based on balanced ideal advantages (Approach 2) choose $p_{1}$ as the best joint venter contractor at the same time. However, Approach 2 has lower complexity than Approach 1, which is easier to calculate the ranking for the joint venter contractors. Here we use another two methods (Approaches 3 and 4) without regard to expert weights of Approaches 1 and 2 to solve the same problem descripted in Section 5.1. The ranking indices of bidimensional attributes are calculated by utilizing Approach 3 as $R_{1}=0.754, R_{2}=0.734$, and $R_{3}=0.708$. The balanced ideal advantages are calculated by utilizing Approach 4 as $R_{1}=0.150, R_{2}=0.130$, and $R_{3}=0.117$. We compare results generated utilized by Approach 3, Approach 4, and the proposed two methods as follows: (1) Decision results of the four methods are consistent with the real decision results; that is, the alternative joint venter contractor $p_{1}$ should be chosen. However, $p_{1}$ has significant advantage over $p_{2}$ and $p_{3}$ utilized by Approach 1. The decision processes of the four approaches involve gathering of the candidate joint venter contractors' objective statistics and the experts' subjective evaluation information. (2) Nevertheless, there was no significant difference on decision values (the ranking indices of bidimensional attributes) of $p_{1}, p_{2}$, and $p_{3}$ utilized by Approach 3. It implicates that expert weights affect the decision results on selecting joint venter contractors for largescale infrastructure projects [26, 28]. (3) Compared with Approach 3, Approach 1 is more helpful for DMs to make 
TABLE 4: Attribute weights evaluated by experts.

\begin{tabular}{|c|c|c|c|c|c|c|c|c|c|c|}
\hline \multirow{2}{*}{ Experts } & \multicolumn{10}{|c|}{ Attributes } \\
\hline & $I_{1}$ & $I_{2}$ & $I_{3}$ & $I_{4}$ & $C_{1}$ & $C_{2}$ & $C_{3}$ & $C_{4}$ & $C_{5}$ & $C_{6}$ \\
\hline$E_{1}$ & $\mathrm{VH}$ & $\mathrm{VH}$ & $\mathrm{DH}$ & $\mathrm{VH}$ & $\mathrm{VH}$ & $\mathrm{DH}$ & $\mathrm{DH}$ & $\mathrm{DH}$ & $\mathrm{VH}$ & $\mathrm{DH}$ \\
\hline$E_{2}$ & $\mathrm{H}$ & VH & VH & DH & $\mathrm{DH}$ & VH & VH & DH & $\mathrm{VH}$ & DH \\
\hline$E_{3}$ & $\mathrm{DH}$ & $\mathrm{H}$ & $\mathrm{DH}$ & $\mathrm{DH}$ & $\mathrm{VH}$ & $\mathrm{VH}$ & DH & $\mathrm{DH}$ & $\mathrm{VH}$ & $\mathrm{VH}$ \\
\hline$E_{4}$ & $\mathrm{VH}$ & $\mathrm{DH}$ & $\mathrm{VH}$ & $\mathrm{DH}$ & $\mathrm{VH}$ & $\mathrm{DH}$ & $\mathrm{H}$ & $\mathrm{DH}$ & $\mathrm{VH}$ & $\mathrm{DH}$ \\
\hline
\end{tabular}

TABLE 5: Evaluation on competitiveness attributes of candidates given by experts.

\begin{tabular}{cccccc}
\hline \multirow{2}{*}{ Candidates } & \multirow{2}{*}{ Attributes } & $E_{1}$ & $E_{2}$ & $E_{3}$ & $E_{4}$ \\
\hline \multirow{4}{*}{$P_{1}$} & $I_{1}$ & $(0.424,0.600,0.750)$ & $(0.418,0.582,0.733)$ & $(0.417,0.583,0.650)$ & $(0.384,0.450,0.682)$ \\
& $I_{2}$ & $(0.359,0.523,0.666)$ & $(0.359,0.521,0.667)$ & $(0.310,0.476,0.619)$ & $(0.357,0.524,0.690)$ \\
& $I_{3}$ & $(0.170,0.330,0.500)$ & $(0.420,0.580,0.750)$ & $(0.585,0.750,0.915)$ & $(0.500,0.665,0.835)$ \\
& $I_{4}$ & $(0.500,0.665,0.835)$ & $(0.250,0.415,0.585)$ & $(0.335,0.500,0.665)$ & $(0.420,0.580,0.750)$ \\
\hline & $I_{2}$ & $(0.236,0.533,0.700)$ & $(0.361,0.533,0.700)$ & $(0.461,0.532,0.767)$ & $(0.431,0.600,0.749)$ \\
& $I_{1}$ & $(0.359,0.521,0.691)$ & $(0.524,0.689,0.810)$ & $(0.357,0.524,0.666)$ & $(0.407,0.570,0.737)$ \\
& $I_{2}$ & $(0.335,0.500,0.665)$ & $(0.335,0.500,0.665)$ & $(0.420,0.580,0.750)$ & $(0.500,0.670,0.830)$ \\
& $I_{3}$ & $(0.170,0.330,0.500)$ & $(0.250,0.420,0.580)$ & $(0.335,0.500,0.665)$ & $(0.400,0.585,0.750)$ \\
\multirow{3}{*}{$P_{3}$} & $I_{4}$ & $(0.451,0.616,0.783)$ & $(0.450,0.616,0.750)$ & $(0.433,0.617,0.749)$ & $(0.434,0.600,0.749)$ \\
& $I_{1}$ & $(0.524,0.690,0.833)$ & $(0.573,0.736,0.857)$ & $(0.383,0.546,0.714)$ & $(0.381,0.547,0.690)$ \\
& $I_{2}$ & $(0.420,0.580,0.750)$ & $(0.170,0.330,0.500)$ & $(0.335,0.500,0.665)$ & $(0.420,0.580,0.750)$ \\
& $I_{3}$ & $(0.170,0.330,0.500)$ & $(0.420,0.580,0.750)$ & $(0.500,0.665,0.750)$ & $(0.170,0.330,0.500)$ \\
\hline
\end{tabular}

TABLE 6: Evaluation on cooperation attributes of candidates given by experts.

\begin{tabular}{cccccc}
\hline \multirow{2}{*}{ Candidates } & \multirow{2}{*}{ Attributes } & $E_{1}$ & $E_{2}$ & $E_{3}$ & $E_{4}$ \\
\hline & & $(0.388,0.557,0.722)$ & $(0.324,0.509,0.676)$ & $(0.417,0.583,0.751)$ & $(0.333,0.499,0.667)$ \\
& $C_{1}$ & $(0.479,0.647,0.812)$ & $(0.390,0.556,0.722)$ & $(0.341,0.507,0.674)$ & $(0.250,0.411,0.583)$ \\
$P_{1}$ & $C_{2}$ & $(0.272,0.437,0.605)$ & $(0.292,0.457,0.626)$ & $(0.411,0.575,0.737)$ & $(0.300,0.465,0.632)$ \\
& $C_{3}$ & $(0.508,0.674,0.840)$ & $(0.653,0.827,0.932)$ & $(0.508,0.673,0.834)$ & $(0.437,0.632,0.786)$ \\
& $C_{4}$ & $(0.458,0.627,0.792)$ & $(0.522,0.688,0.879)$ & $(0.355,0.519,0.682)$ & $(0.598,0.771,0.916)$ \\
& $C_{5}$ & $(0.120,0.233,0.400)$ & $(0.232,0.396,0.566)$ & $(0.195,0.333,0.487)$ & $(0.176,0.315,0.468)$ \\
\hline & $C_{6}$ & $(0.277,0.444,0.612)$ & $(0.321,0.457,0.605)$ & $(0.332,0.488,0.656)$ & $(0.288,0.455,0.503)$ \\
& $C_{1}$ & $(0.402,0.565,0.728)$ & $(0.349,0.517,0.684)$ & $(0.367,0.533,0.701)$ & $(0.359,0.524,0.693)$ \\
$P_{2}$ & $C_{2}$ & $(0.351,0.516,0.684)$ & $(0.234,0.400,0.567)$ & $(0.409,0.599,0.776)$ & $(0.443,0.607,0.758)$ \\
& $C_{3}$ & $(0.351,0.516,0.684)$ & $(0.275,0.441,0.610)$ & $(0.334,0.525,0.667)$ & $(0.368,0.517,0.691)$ \\
& $C_{4}$ & $(0.217,0.383,0.551)$ & $(0.433,0.600,0.767)$ & $(0.317,0.508,0.684)$ & $(0.367,0.533,0.701)$ \\
& $C_{5}$ & $(0.177,0.328,0.486)$ & $(0.134,0.266,0.434)$ & $(0.178,0.327,0.487)$ & $(0.178,0.311,0.461)$ \\
\hline & $C_{6}$ & $(0.209,0.374,0.543)$ & $(0.250,0.395,0.553)$ & $(0.166,0.313,0.469)$ & $(0.208,0.347,0.389)$ \\
& $C_{1}$ & $(0.395,0.563,0.730)$ & $(0.375,0.541,0.710)$ & $(0.241,0.397,0.572)$ & $(0.407,0.572,0.741)$ \\
$P_{3}$ & $C_{2}$ & $(0.406,0.573,0.730)$ & $(0.334,0.490,0.666)$ & $(0.396,0.561,0.720)$ & $(0.400,0.562,0.730)$ \\
& $C_{3}$ & $(0.396,0.562,0.730)$ & $(0.313,0.479,0.646)$ & $(0.250,0.417,0.584)$ & $(0.345,0.509,0.678)$ \\
& $C_{4}$ & $(0.396,0.561,0.731)$ & $(0.240,0.406,0.574)$ & $(0.345,0.510,0.677)$ & $(0.302,0.459,0.638)$ \\
& $C_{5}$ & $(0.153,0.291,0.459)$ & $(0.138,0.264,0.432)$ & $(0.153,0.291,0.459)$ & $(0.180,0.327,0.483)$ \\
\hline
\end{tabular}

a decision. This is because Approaches 3 and 4 just take into account competitive attribute weights and cooperation attribute weights, while our proposed approaches also consider the judgment abilities of individual experts except for the attribute weights.

\section{Conclusions}

This paper developed a matrix analysis model to support decision systems for joint venter contractor selection of bidding in construction projects based on competitive attributes 
TABLE 7: The integrated decision matrix.

\begin{tabular}{lccr}
\hline Attributes & & Candidates & $P_{3}$ \\
\hline$I_{1}$ & $P_{1}$ & $P_{2}$ & $(0.377,0.521,0.645)$ \\
$I_{2}$ & $(0.351,0.476,0.602)$ & $(0.308,0.465,0.617)$ & $(0.403,0.543,0.665)$ \\
$I_{3}$ & $(0.259,0.439,0.561)$ & $(0.350,0.490,0.654)$ & $(0.284,0.421,0.564)$ \\
$I_{4}$ & $(0.342,0.479,0.623)$ & $(0.236,0.47,0.379,0.520)$ & $(0.267,0.404,0.531)$ \\
$C_{1}$ & $(0.322,0.461,0.605)$ & $(0.258,0.465,0.617)$ & $(0.178,0.306,0.422)$ \\
$C_{2}$ & $(0.312,0.458,0.600)$ & $(0.315,0.456,0.597)$ & $(0.303,0.442,0.586)$ \\
$C_{3}$ & $(0.319,0.460,0.602)$ & $(0.222,0.445,0.586)$ & $(0.326,0.464,0.604)$ \\
$C_{4}$ & $(0.319,0.460,0.602)$ & $(0.281,0.424,0.563)$ & $(0.280,0.421,0.563)$ \\
$C_{5}$ & $(0.452,0.600,0.724)$ & $(0.279,0.426,0.570)$ & $(0.275,0.414,0.559)$ \\
$C_{6}$ & $(0.408,0.550,0.692)$ & $(0.110,0.262,0.397)$ & $(0.131,0.205,0.388)$ \\
\hline
\end{tabular}

TABLE 8: The weighted integrated decision matrix.

\begin{tabular}{lccr}
\hline Attributes & & Candidates & \\
& $P_{1}$ & $P_{2}$ & $P_{3}$ \\
\hline$I_{1}$ & $(0.200,0.335,0.489)$ & $(0.173,0.327,0.501)$ & $(0.212,0.367,0.524)$ \\
$I_{2}$ & $(0.166,0.309,0.458)$ & $(0.197,0.344,0.534)$ & $(0.197,0.344,0.534)$ \\
$I_{3}$ & $(0.220,0.375,0.530)$ & $(0.213,0.368,0.519)$ & $(0.182,0.329,0.479)$ \\
$I_{4}$ & $(0.214,0.372,0.514)$ & $(0.157,0.306,0.442)$ & $(0.178,0.326,0.451)$ \\
$C_{1}$ & $(0.198,0.354,0.510)$ & $(0.164,0.303,0.432)$ & $(0.113,0.237,0.359)$ \\
$C_{2}$ & $(0.204,0.358,0.512)$ & $(0.207,0.355,0.507)$ & $(0.193,0.344,0.498)$ \\
$C_{3}$ & $(0.164,0.308,0.451)$ & $(0.136,0.336,0.481)$ & $(0.200,0.350,0.495)$ \\
$C_{4}$ & $(0.319,0.510,0.615)$ & $(0.198,0.360,0.479)$ & $(0.198,0.358,0.479)$ \\
$C_{5}$ & $(0.233,0.388,0.588)$ & $(0.159,0.301,0.485)$ & $(0.157,0.292,0.475)$ \\
$C_{6}$ & $(0.099,0.220,0.346)$ & $(0.072,0.214,0.337)$ & $(0.086,0.167,0.330)$ \\
\hline
\end{tabular}

TABLE 9: The distances of the candidate joint venter contractors from the PIS and NIS.

\begin{tabular}{lcr}
\hline Candidates & \multicolumn{1}{c}{ Distances } \\
\hline$P_{1}$ & $d_{i}^{+}$ & 13.250 \\
$P_{2}$ & 5.928 & 13.025 \\
$P_{3}$ & 6.913 & 10.603 \\
\hline
\end{tabular}

TABLE 10: The ranking indices and overall values of bidimensional attributes in the method based on balanced ideal advantages.

\begin{tabular}{lccc}
\hline \multirow{2}{*}{ Candidates } & \multicolumn{2}{c}{ Overall values of bidimensional attributes } & $y_{i}$ \\
& $x_{i}$ & 0.371 & Ranking indices $R_{i}$ \\
\hline$P_{1}$ & 0.663 & 0.331 & 0.123 \\
$P_{2}$ & 0.673 & 0.316 & 0.111 \\
$P_{3}$ & 0.668 & 0.106 \\
\hline
\end{tabular}

and cooperation attributes. Then, two decision approaches based on competitive attributes and cooperation attributes are proposed. The specific measurement methods of each index in these two approaches are given. These approaches put forward the bidimensional and balanced performance problems and propose two balanced information integration and performance ranking methods. The proposed two methods both choose $p_{1}$ as the best joint venter contractor at the same time. However, Approach 2 has lower complexity than Approach 1, which is easier to calculate the ranking for the joint venter contractors. Joint venter contractor selection of bidding in island and tunnel engineering diagram of the 
HZMB as a case study including three candidate units is used to illustrate our approaches. As a result of limitation of resources and different preference of DMs, we can further modify the model and increase some objectives attributes for the model. In addition, theory thoughts put forward in this paper are hoping to bring some enlightenment for bidding problems in construction projects.

\section{Conflicts of Interest}

The authors declare that there are no conflicts of interest regarding the publication of this paper.

\section{Acknowledgments}

This work was partly supported by the National Natural Science Foundation of Key Projects (no. 71390521), the National Natural Science Foundation of China (nos. 91646123, 71671088, 71571098, 71501102, and 71701090), Discovery Project from Australia Research Council (no. DP170104612), and the program for Outstanding Ph.D. Candidate of Nanjing University (nos. 201601A001 and 201702B041).

\section{References}

[1] W. Gao and K. Hong, "The portfolio balanced risk index model and analysis of examples of large-scale infrastructure project," Complexity, vol. 2017, Article ID 5174613, 13 pages, 2017.

[2] N. M. Gonzalez, T. C. Carvalho, and C. C. Miers, "Cloud resource management: towards efficient execution of large-scale scientific applications and workflows on complex infrastructures," Journal of Cloud Computing, vol. 6, no. 1, 2017.

[3] S. K. Sundararajan and C. Tseng, "Managing Project Performance Risks under Uncertainty: Using a Dynamic Capital Structure Approach in Infrastructure Project Financing," Journal of Construction Engineering and Management, vol. 143, no. 8, 2017.

[4] M. Efatmaneshnik and M. J. Ryan, "On optimal modularity for system construction,” Complexity, vol. 21, no. 5, pp. 176-189, 2016.

[5] I. C. Cardenas, H. Voordijk, and G. Dewulf, "Beyond theory: Towards a probabilistic causation model to support project governance in infrastructure projects," International Journal of Project Management, vol. 35, no. 3, pp. 432-450, 2017.

[6] N. Arranz and J. C. Fdez de Arroyabe, "Complex joint R\&D projects: From empirical evidence to managerial implications," Complexity, vol. 15, no. 1, pp. 61-70, 2009.

[7] A. Rostami and C. F. Oduoza, "Key risks in construction projects in Italy: contractors' perspective," Engineering, Construction and Architectural Management, vol. 24, no. 3, pp. 451462, 2017.

[8] Z. Hatush and M. Skitmore, "Contractor Selection Using Multicriteria Utility Theory: An Additive Model," Building and Environment, vol. 33, no. 2-3, pp. 105-115, 1998.

[9] K. C. Lam, S. Thomas Ng, T. hu, M. Skitmore, and S. O. Cheung, "Decision support system for contractor pre-qualification-artificial neural network model," Engineering, Construction and Architectural Management, vol. 7, no. 3, pp. 251266, 2000.
[10] L. Y. Shen, W. Lu, Q. Shen, and H. Li, "A computer-aided decision support system for assessing a contractor's competitiveness," Automation in Construction, vol. 12, no. 5, pp. 577-587, 2003.

[11] A. Nureize and J. Watada, "Multi-attribute decision making in contractor selection under hybrid uncertainty," Journal of Advanced Computational Intelligence and Intelligent Informatics, vol. 15, no. 4, pp. 465-472, 2011.

[12] Z. Zhao, C. Tang, X. Zhang, and M. Skitmore, "Agglomeration and competitive position of contractors in the international construction sector," Journal of Construction Engineering and Management, vol. 143, no. 6, 2017.

[13] P. S.-W. Fong and S. K.-Y. Choi, "Final contractor selection using the analytical hierarchy process," Construction Management and Economics, vol. 18, no. 5, pp. 547-557, 2000.

[14] E. K. Zavadskas, Z. Turskis, and J. Antucheviciene, "Selecting a contractor by using a novel method for multiple attribute analysis: Weighted aggregated sum product assessment with grey values (WASPAS-G)," Studies in Informatics and Control, vol. 24, no. 2, pp. 141-150, 2015.

[15] V. Yousefi, S. H. Yakhchali, M. Khanzadi, E. Mehrabanfar, and J. Šaparauskas, "Proposing a neural network model to predict time and cost claims in construction projects," Journal of Civil Engineering and Management, vol. 22, no. 7, pp. 967-978, 2016.

[16] K.-S. Kim, S.-Y. Kim, D. Y. Kim, and Y.-K. Huh, "Multivariate discriminant analysis for assessing residential development projects from a contractor's perspective," KSCE Journal of Civil Engineering, vol. 21, no. 4, pp. 1069-1075, 2017.

[17] M. Gunduz, Y. Nielsen, and M. Ozdemir, "Fuzzy assessment model to estimate the probability of delay in Turkish construction projects," Journal of Management in Engineering, vol. 31, no. 4, Article ID 4014055, 2015.

[18] M. K. Tehrani, A. Fereidunian, and H. Lesani, "Financial planning for the preventive maintenance of power distribution systems via fuzzy AHP," Complexity, vol. 21, no. 3, pp. 36-46, 2016.

[19] M. S. El-Abbasy, T. Zayed, M. Ahmed, H. Alzraiee, and M. Abouhamad, "Contractor selection model for highway projects using integrated simulation and analytic network process," Journal of Construction Engineering and Management, vol. 139, no. 7, pp. 755-767, 2013.

[20] Y. Konno, "An empirical analysis of the discontinuance of business for startup contractors and property companies in Japan," Journal of Financial Management of Property and Construction, vol. 20, no. 1, pp. 50-64, 2015.

[21] J. Liu, S. Zhang, C. Wu, J. Liang, X. Wang, and K. L. Teo, "A hybrid approach to constrained global optimization," Applied Soft Computing, vol. 47, pp. 281-294, 2016.

[22] Y. Tan, B. Xue, and Y. T. Cheung, "Relationships between main contractors and subcontractors and their impacts on main contractor competitiveness: an empirical study in Hong Kong," Journal of Construction Engineering and Management, vol. 143, no. 7, 2017.

[23] P. E. Love and P. Teo, "Statistical Analysis of Injury and Nonconformance Frequencies in Construction: Negative Binomial Regression Model," Journal of Construction Engineering and Management, vol. 143, no. 8, p. 05017011, 2017.

[24] M. Taghipour, F. Seraj, M. A. Hassani, and S. F. Kheirabadi, "Risk analysis in the management of urban construction projects from the perspective of the employer and the contractor," vol. 4, pp. 356-373, 2015. 
[25] C. Zhao, C. Wu, J. Chai et al., "Decomposition-based multiobjective firefly algorithm for RFID network planning with uncertainty," Applied Soft Computing, vol. 55, pp. 549-564, 2017.

[26] J. Chai, C. Wu, C. Zhao et al., "Reference tag supported RFID tracking using robust support vector regression and Kalman filter," Advanced Engineering Informatics, vol. 32, pp. 1-10, 2017.

[27] J. Liu, K. L. Teo, X. Wang, and C. Wu, "An exact penalty function-based differential search algorithm for constrained global optimization," Soft Computing, vol. 20, no. 4, pp. 13051313, 2016.

[28] X. Zhang, C. Wu, J. Li et al., "Binary artificial algae algorithm for multidimensional knapsack problems," Applied Soft Computing, vol. 43, pp. 583-595, 2016.

[29] V. Singh, N. Gu, and X. Wang, "A theoretical framework of a BIM-based multi-disciplinary collaboration platform," Automation in Construction, vol. 20, no. 2, pp. 134-144, 2011.

[30] L. Zhang, M. J. Skibniewski, X. Wu, Y. Chen, and Q. Deng, "A probabilistic approach for safety risk analysis in metro construction," Safety Science, vol. 63, pp. 8-17, 2014.

[31] R. Liang, Z. Sheng, F. Xu, and C. Wu, "Bidding Strategy to Support Decision-Making Based on Comprehensive Information in Construction Projects," Discrete Dynamics in Nature and Society, vol. 2016, Article ID 4643630, 15 pages, 2016.

[32] R. Liang, Z. Dong, Z. Sheng, X. Wang, and C. Wu, "Case study of selecting decision-making schemes in large-scale infrastructure projects," Journal of Infrastructure Systems, vol. 23, no. 4, 2017.

[33] C. J. Lin and W. W. Wu, "A causal analytical method for group decision-making under fuzzy environment," Expert Systems with Applications, vol. 34, no. 1, pp. 205-213, 2008.

[34] A. Kaufmann and M. M. Gupta, Gupta Introduction to Fuzzy Arithmetic-Theory and Applications, Thomson Computer Press, New York, NY, USA, 1991.

[35] L. A. Zadeh, "The concept of a linguistic variable and its application to approximate reasoning-II," Information Sciences, vol. 8, no. 4, pp. 301-357, 1975.

[36] Z. Chen, P. Liu, and Z. Pei, "An approach to multiple attribute group decision making based on linguistic intuitionistic fuzzy numbers," International Journal of Computational Intelligence Systems, vol. 8, no. 4, pp. 747-760, 2015.

[37] M. F. Chen and G. H. Tzeng, "Combining grey relation and TOPSIS concepts for selecting an expatriate host country," Mathematical and Computer Modelling, vol. 40, no. 13, pp. 14731490, 2004.

[38] B.-G. Hwang, X. Zhao, and G. S. Yu, "Risk identification and allocation in underground rail construction joint ventures: contractors' perspective," Journal of Civil Engineering and Management, vol. 22, no. 6, pp. 758-767, 2016.

[39] H.-L. Chi, S.-C. Kang, and X. Wang, "Research trends and opportunities of augmented reality applications in architecture, engineering, and construction," Automation in Construction, vol. 33, pp. 116-122, 2013.

[40] X. Deng, S. P. Low, Q. Li, and X. Zhao, "Developing competitive advantages in political risk management for international construction enterprises," Journal of Construction Engineering and Management, vol. 140, no. 9, article 04014040, 2014.

[41] M. Darvish, M. Yasaei, and A. Saeedi, "Application of the graph theory and matrix methods to contractor ranking," International Journal of Project Management, vol. 27, no. 6, pp. 610-619, 2009.

[42] A. M. Anvuur and M. M. Kumaraswamy, "Conceptual model of partnering and alliancing," Journal of Construction Engineering and Management, vol. 133, no. 3, pp. 225-234, 2007.
[43] X. Deng, S. P. Low, Q. Li, and X. Zhao, "Developing competitive advantages in political risk management for international construction enterprises," Journal of Construction Engineering and Management, vol. 140, no. 9, 2014.

[44] B. G. Hwang and H. B. Ng, "Project network management: risks and contributors from the viewpoint of contractors and sub-contractors," Technological and Economic Development of Economy, vol. 22, no. 4, pp. 631-648, 2016.

[45] Y. Fu, Y. Chen, S. Zhang, and W. Wang, "Promoting cooperation in construction projects: an integrated approach of contractual incentive and trust," Construction Management and Economics, vol. 33, no. 8, pp. 653-670, 2015.

[46] F. Khosrowshahi, "Neural network model for contractors' prequalification for local authority projects," Engineering, Construction and Architectural Management, vol. 6, no. 3, pp. 315328, 1999. 


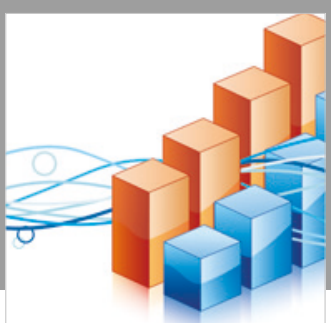

Advances in

Operations Research

\section{-n-m}
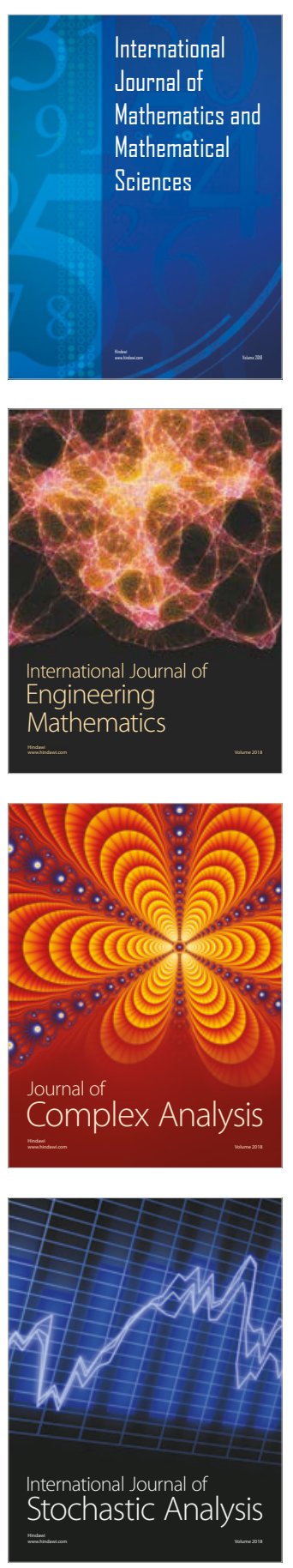
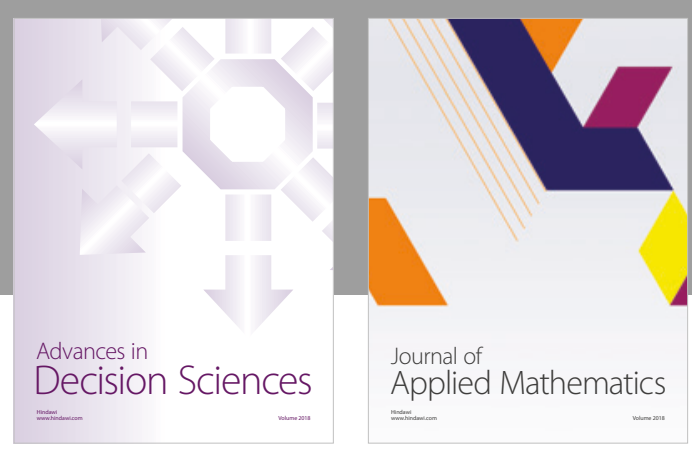

Journal of

Applied Mathematics
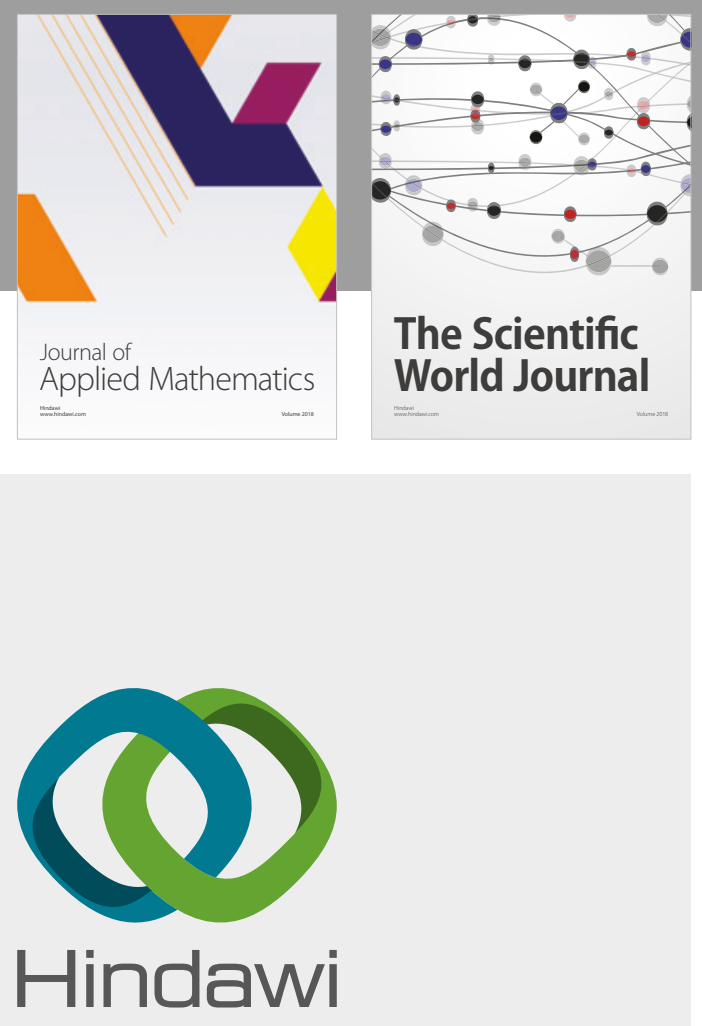

Submit your manuscripts at

www.hindawi.com

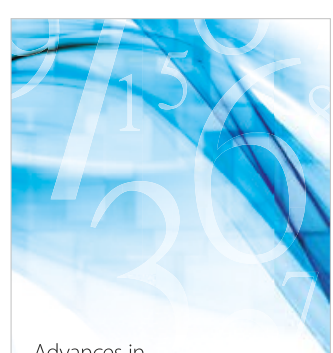

Advances in
Numerical Analysis
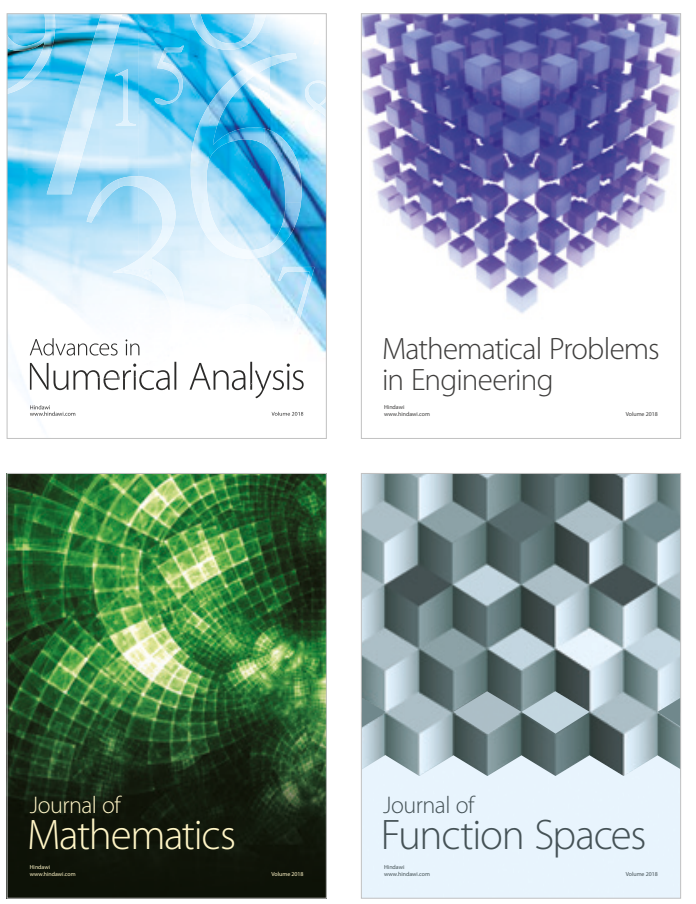

Mathematical Problems in Engineering

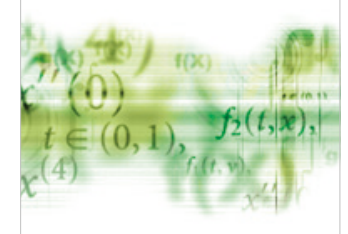

International Journal of

Differential Equations

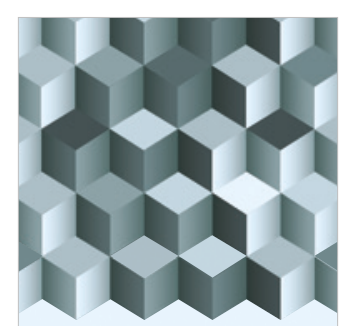

Journal of

Function Spaces
The Scientific

World Journal

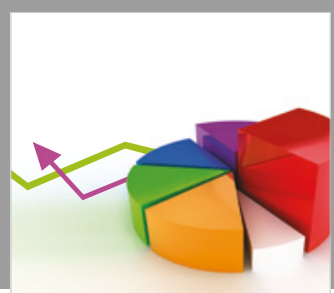

Journal of

Probability and Statistics
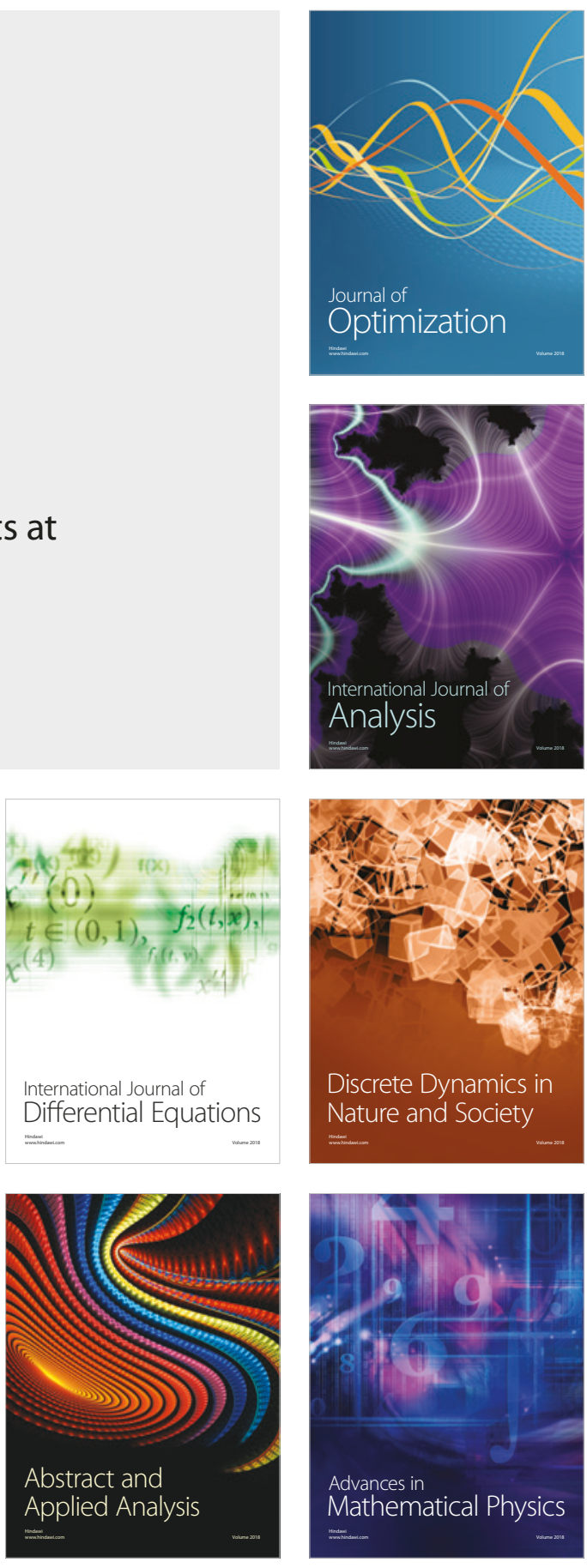